Revue d'histoire de l'Amérique française

REVUE D.HISTOIRE DE L'AMÉRIQUE FRANÇAISE

\title{
SOEUR THÉRÈSE-DU-CARMEL, s.s.j. (Lucienne Blais), Licenciée \\ en Pédagogie, Bibliographie analytique de l'oeuvre de Félix-Antoine Savard. Préface de Luc Lacourcière, Fides, Montréal, 1967. 229 p.
}

\section{Lionel Groulx}

Volume 21, numéro 1, juin 1967

URI : https://id.erudit.org/iderudit/302658ar

DOI : https://doi.org/10.7202/302658ar

Aller au sommaire du numéro

Éditeur(s)

Institut d'histoire de l'Amérique française

ISSN

0035-2357 (imprimé)

1492-1383 (numérique)

Découvrir la revue

Citer ce compte rendu

Groulx, L. (1967). Compte rendu de [SOEUR THÉRÈSE-DU-CARMEL, s.s.j.

(Lucienne Blais), Licenciée en Pédagogie, Bibliographie analytique de l'oeuvre de Félix-Antoine Savard. Préface de Luc Lacourcière, Fides, Montréal, 1967. 229 p.] Revue d'histoire de l'Amérique française, 21(1), 145-146.

https://doi.org/10.7202/302658ar d'utilisation que vous pouvez consulter en ligne. 
SEUR THÉRÈSE-DU-CARMEL, s.s.j. (Lucienne Blais), Licenciée en Pédagogie, Bibliographie analytique de l'œuvre de FélixAntoine Savard. Préface de Luc Lacourcière, Fides, Montréal, 1967. 229 pages. 
Nous sommes au vingt-cinquième anniversaire de Menaud, maître-draveur. L'on a voulu, par cette bibliographie, rendre hommages à l'auteur d'un roman qui tient de l'épopée et qui, dans le temps, révéla un grand écrivain. Personne ne contestera l'opportunité de cet hommage. L'ouvrage se divise en quatre parties: notice biographique (trop courte) de l'écrivain, catalogue de ses œuvres, sources à consulter sur l'auteur, index alphabétique et table des matières. Cette table très complète, un numérotage très exact des noms et des sujets d'articles abordés rend très facile la consultation de ce livre.

Trop courte, avons-nous dit, la notice biographique nous renseigne pourtant sur la formation de l'écrivain et sur l'originalité de son œuvre. Jeunesse tôt éveillée au mystère des bois et de la nature vierge, à la virilité du pays, l'enseignement des lettres, le ministère paroissial, dans les montagnes, dans les chantiers, rencontres de draveurs, fondation de paroisse, mission de colonisateur en Abitibi, retour à l'enseignement, mais universitaire cette fois, conférences sur Mistral, à Laval, professeur agrégé et titulaire de la Chaire de poésie française, doyen de la faculté des Lettres, retraite aux Eboulements-en-Bas. Telle se dessine jusqu'à l'heure, la carrière de Félix-Antoine Savard.

La "Bibliographie analytique" nous réserve une première révélation: l'abondance de l'œuvre de l'abbé Savard avant $M e$ naud et après Menaud, abondance qui se déverse en des sermons, des causeries, des conférences sur divers sujets, en articles de journaux et de revues. Puis, après Menaud maître-draveur, viennent les autres grandes œuvres: L'Abatis, Le Minuit, Le Barachois, Martin et le pauvre, la Folle, La Dalle-des-Morts. On connaît les thèmes inspirateurs du prosateur-poète. De plus élevés, il ne s'en peut guère pour l'écrivain canadien-français qui, quoique l'on prétende, veut atteindre à la réelle originalité, faire de la littérature, non point cosmopolite par prétention d'universalisme, mais agir en écrivain de son fonds, de sa qualité de Français du nouveau-monde, de son pays, de son ascendance historique. Donc les thèmes que voici: patrie québecoise, traditions, humanisme, éducation, vie paysanne, folklore, légende. Né en 1896, Mgr Savard n'est donc âgé que de 71 ans. Que ne pas attendre de cet homme encore jeune et resté jeune, l'esprit toujours effervescent, encore bruissant, hanté de beaux ouvrages en préparation et qui s'est déjà placé au sommet de nos lettres.

C'est dire que cette bibliographie analytique n'est que la première tranche d'une vie encore loin de son couchant.

LIONEL GROULX, ptre 